\title{
Un estudio de caso: la rehabilitación de los edificios de viviendas del barrio de La Mina en Sant Adrià del Besòs (Barcelona). Análisis funcional y de las condiciones de seguridad, habitabilidad y mantenimiento
}

\author{
A case study: the rehabilitation of residential buildings in La \\ Mina district in Sant Adrià del Besòs (Barcelona). Functional \\ analysis and assessment of safety conditions, habitability \\ and maintenance
}

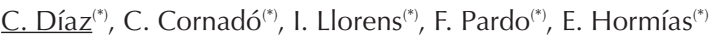

\section{RESUMEN}

El barrio de La Mina es un conjunto de 2.727 viviendas de promoción pública construido durante los años 1968-74, en pleno boom edificatorio del sector. Se caracteriza por la mezcla de tipos edificatorios y sistemas constructivos utilizados, destacando, por su relativa singularidad, la presencia de edificios en los que se aplicó la técnica de los denominados encofrados-túnel.

El presente trabajo expone y comenta el contenido del estudio técnico elaborado a raíz de la confección del Plan Especial de Transformación y Mejora del barrio, que prevé la rehabilitación de los edificios y la recalificación urbanística y social del barrio, fuertemente estigmatizado por su elevada conflictividad. En dicho estudio se analizaron detalladamente los aspectos funcionales, las condiciones de seguridad estructural, el grado de aislamiento térmico, y las condiciones acústicas, de protección contra incendios, accesibilidad y mantenimiento de los edificios, elaborándose propuestas de intervención dirigidas a reducir las deficiencias más notables.

\section{$112-7$}

Palabras clave: rehabilitación de edificios, patología de la construcción, hormigón armado, industrialización, encofrado-túnel

\section{SUMMARY}

The La Mina district is a public housing development. Consisting of 2727 apartments which were built during the years 1968-74 at the height of the building sector boom, it is characterized by the mixture of building types and building methods employed and is remarkable for the use of the tunnel formwork technique.

This paper presents and discusses the contents of the technical study which was prepared as a part of the Plan for Transformation and Improvement of the neighbourhood. The Plan provides for the rehabilitation of buildings and the urban reclassification and social regeneration of the neighbourhood, which is highly stigmatized as a problem area. The functional and structural safety conditions, the level of thermal and acoustic insulation, fire protection, accessibility and maintenance conditions were all analysed in detail in the technical study. In addition, several proposals were put forward for interventions aimed at reducing the most glaring deficiencies.

Keywords: building rehabilitation, building pathology, reinforced concrete, industrialization, tunnel formwork 
1. Ubicación del barrio de la Mina en el entorno urbano de Barcelona.

2. Visión global de los diferentes bloques de viviendas del barrio.

1 La denominación de DITEC corresponde al acrónimo del grupo de investigación de la Universidad Politécnica de Cataluña que lleva por título Diagnosis y Técnicas de Intervención en la Restauración y Rehabilitación de Edificios.

${ }^{2}$ La resolución, aparecida en el BOE de 15 de enero de 2008, de la Presidencia del Jurado del Premio Nacional de Urbanismo de 2006 hacía referencia al galardón de la siguiente forma: "En su modalidad de premio a un Trabajo, Plan o Proyecto de Ordenación Urbanística, al Plan de Transformación del Barrio de La Mina, presentado por el Consorcio del Barrio de la Mina, y cuyo Plan Especial de Reordenación y Mejora ha sido redactado por los arquitectos D. Sebastià Jornet, D. Carles Llop y D. Joan Enric Pastor, el Jurado ha valorado el carácter integrado de la actuación, que se plantea sobre un barrio surgido a finales de los años sesenta, de marcado carácter marginal y socialmente muy degradado, y que se apoya en un Plan Especial de alta calidad técnica".

${ }^{3}$ Las diversas técnicas constructivas aplicadas en Cataluña en los conjuntos residenciales de vivienda masiva, durante los años del desarrollismo económico de la segunda mitad del s. $X X$, se relacionan y analizan en la tesis doctoral de César Díaz (1).

${ }^{4}$ En el articulo: Algunas consideraciones sobre la historia de la industrialización de la construcción de viviendas durante el Desarrollismo (1960-1975) (2) se analiza la aportación bilbaína al debate de la industrialización de la vivienda dentro del contexto socioeconómico cambiante que llevaba a la necesidad de adaptarse a las nuevas tecnologías y materiales que aparecían en él.

\section{OBJETIVO DEL ESTUDIO}

En el presente trabajo se exponen el contenido y el proceso de elaboración de la propuesta de intervención referente a un conjunto de viviendas construido entre los años 1968 y 1974 en la periferia de Barcelona, con el fin de aportar una experiencia de diagnosis, análisis y proceso de justificación de decisiones de actuación cuyo conocimiento pueda resultar útil y aplicable a otras situaciones de similar temática, ya sea en el ámbito de la rehabilitación de un conjunto residencial reciente, o bien en el más restringido y específico de la tecnología del encofrado-túnel, prácticamente en desuso en la construcción actual, utilizada en dicho barrio en un significativo número de edificios y en otros muchos erigidos durante el mismo periodo.
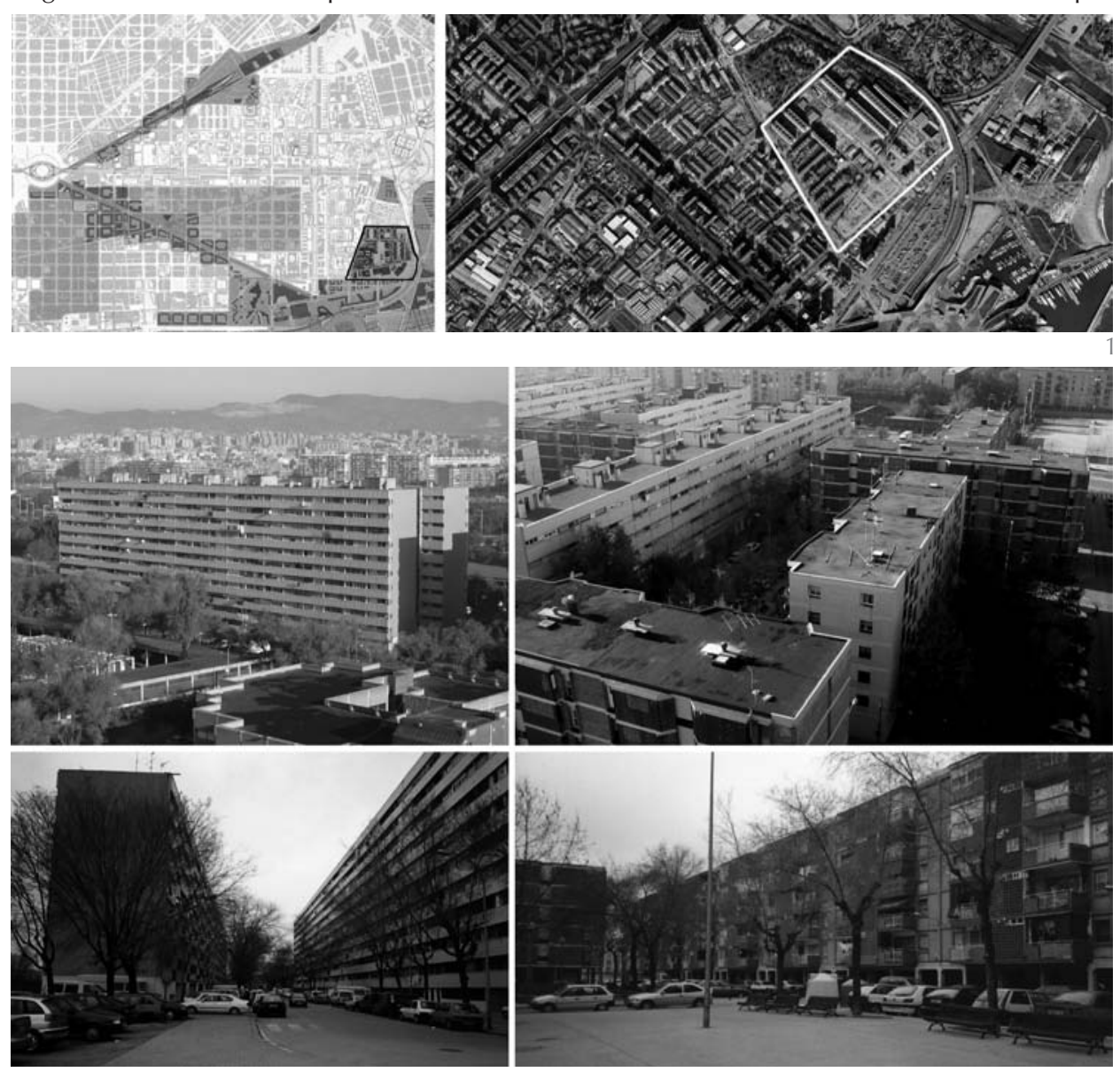

\section{FUENTES DE LA INFORMACIÓN}

La información recopilada para la confección de este artículo proviene en su mayor parte de la obtenida a raíz de la realización del estudio técnico sobre las condiciones constructivas, de habitabilidad y de mantenimiento de los edificios del barrio, elaborado por los miembros del Departamento de Construcciones Arquitectónicas I de la Universidad Politécnica de Cataluña, integrados en el grupo de investigación DITEC ${ }^{1}$. Dicho estudio técnico es parte integrante de la documentación del
Plan Especial de Transformación y Mejora del barrio, el cual obtuvo el Premio Nacional de Urbanismo otorgado por el Ministerio de la Vivienda del Estado español ${ }^{2}$ y ha obtenido más recientemente el premio Europeo de Urbanismo otorgado por el Conseil Européen des Urbanistes. Los datos del estudio inicial han sido complementados con la información recogida a lo largo de los proyectos y las intervenciones de mejora, reforma y rehabilitación de los edificios, realizados y dirigidos por miembros del citado grupo de investigación.

\section{CONTEXTO SOCIAL, URBANO Y TECNOLÓGICO DEL BARRIO DE LA MINA}

El barrio de La Mina se halla ubicado en uno de los límites de Barcelona con el municipio 


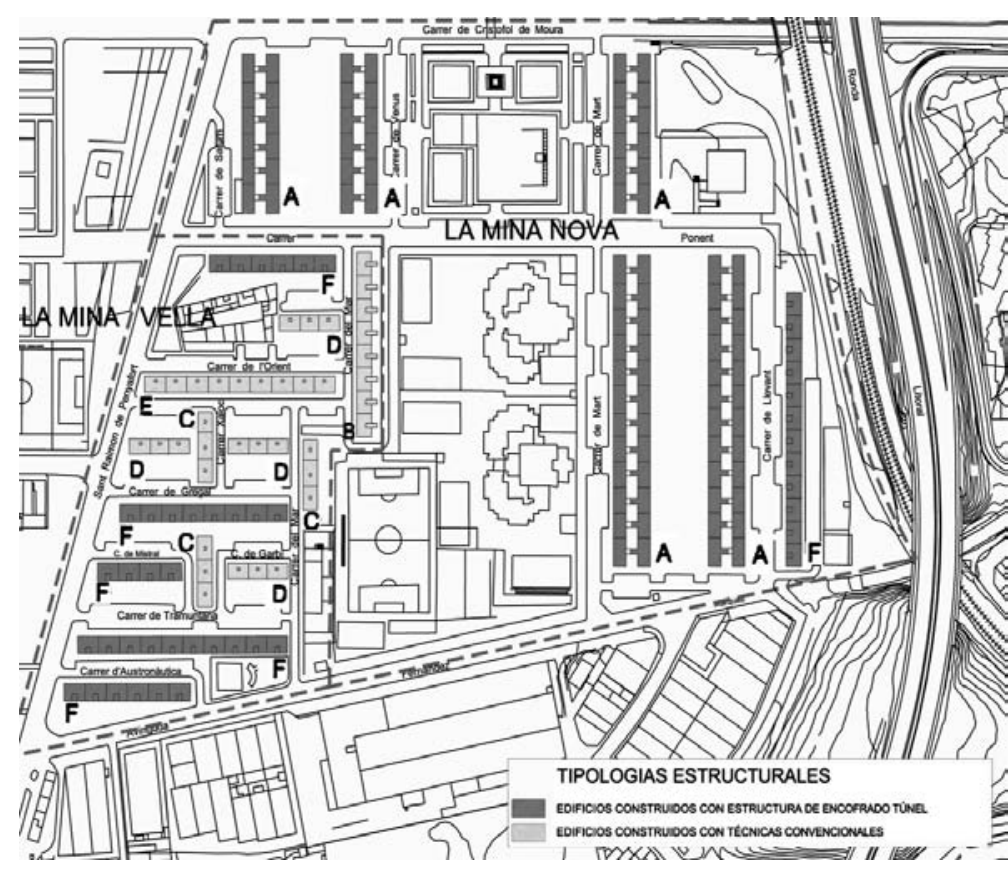

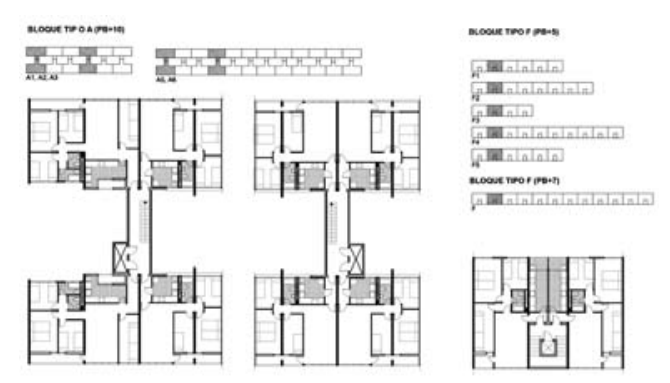
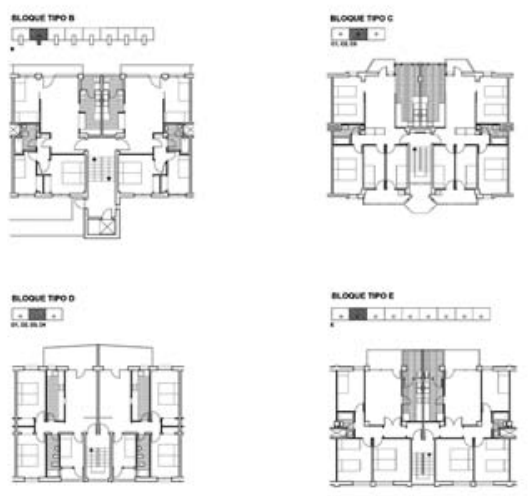

4

dilatada fase de planeamiento, iniciada en 1957, se hallan en el origen de su relativa singularidad morfológica y tecnológica, con edificios muy diferenciados tipológicamente, construidos con técnicas propias de unos años en los que el hormigón armado ampliaba y diversificaba sus formas de aplicación para dar respuesta a la creciente demanda del sector ${ }^{3-4}$.

La configuración urbana del barrio corresponde a la de las áreas de nueva creación de la época, en donde los edificios se liberan de las alineaciones de los viales de las calles y conforman bloques aislados de altura diversa. En su conjunto, los edificios acogen 2.727 viviendas que alojan a más de 15.000 habitantes. Atendiendo a su localización se pueden distinguir dos zonas bien diferenciadas: una de ellas -la denominada Mina Vieja- agrupa 855 viviendas distribuidas en 13 edificios en forma de bloques lineales aislados de 6 plantas de altura (tipos C, D y E) y uno de 14 plantas (tipo B), mientras que la otra zona -la denominada Mina Nueva- agrupa a 1.872 viviendas distribuidas en 5 edificios de 11 plantas de altura y uno de 8 plantas (tipos A y F, respectivamente) (Figuras 2, 3 y 4 ).

\section{EL ENCUENTRO DE DOS CONCEPCIONES TÉCNICAS}

El largo proceso de gestión y de trámites administrativos que precedió al inicio de la construcción de los edificios y que prosiguió incluso durante los años posteriores, explica que en el mismo barrio puedan hallarse, no sólo concepciones diferentes en la forma de proyectar los edificios, sino técnicas constructivas muy diversas, cuya elección cabe interpretarla fundamentalmente en función de las diferencias en la adjudicación de las obras y de los criterios aplicados en cada caso según fuera el momento y el tamaño del lote adjudicado. Es por ello que podemos distinguir en La Mina una primera fase de menor magnitud, concentrada en La Mina Vieja, de edificios construidos con la técnicas usuales de la época a base de pilares o pórticos de hormigón armado, forjados reticulares o de viguetas de hormigón y cerramientos a base de ladrillo visto o revestido, y una segunda fase, de mayor magnitud y extensión, en la que se utiliza la innovadora técnica del encofrado-túnel para construir el último lote de 2.214 viviendas que ponía fin a la edificación residencial del barrio ${ }^{5}$.

\section{LA TÉCNICA DEL ENCOFRADO-TÚNEL}

De hecho, con la técnica del encofrado-túnel se pretendía conseguir un proceso racionalizado y actualizado en la construcción de la vivienda masiva de la época a costos optimizados, el cual obligaba a una fuerte coordinación entre los equipos técnicos redactores de los proyectos y las empresas constructoras adjudicatarias, que debían disponer de los recursos económicos suficientes para la financiación del potente utillaje que requería la aplicación de dicha técnica, sólo al alcance de algunas grandes empresas constructoras del sector.

Concretamente, los sistemas a base de encofrados-túnel se diferencian por tener como elementos distintivos unos encofrados de gran tamaño, denominados túnel, que sirven para dar forma a muros y losas a la vez, de forma que las estructuras resultantes se componen de paredes de carga de hormigón armado
3. Plano del barrio de La Mina.

4. Plantas tipo de los edificios. Los bloques A y F son los construidos con encofrado-túnel; los bloques B, C, D y E, con técnicas convencionales de hormigón armado.

\footnotetext{
${ }^{5}$ La apuesta por la innovación tecnológica en proyectos de obra pública ha sido una constante desde aquél período hasta la fecha. Una de las experiencias más recientes en Cataluña fue el Concurso de Innovación Tecnológica convocado en 2006 y 2007 por el INCASOL, que se planteaba con el objetivo de incorporar mejoras en la construcción de viviendas, concretamente de la calidad, la seguridad, el control en la ejecución, la sostenibilidad, la eficiencia energética, y la eficacia en la promoción. Se premiaron seis proyectos que en su conjunto caracterizan de forma clara las posibilidades de la innovación e industrialización de la vivienda en España (3).
} 
5. Imágenes tomadas durante la elevación y posicionado de uno de los encofrado-túnel.

6. Metodología aplicada en el Estudio Técnico sobre las condiciones constructivas de los edificios.

${ }^{6}$ Una descripción muy detallada de los sistemas de encofrado-túnel utilizados en la época de construcción del barrio de La Mina la facilita Manuel Cabrera Fernández-Pujol en uno de los Cuadernos del Gabinete Técnico (4). El libro de Alfonso del Águila García titulado Las tecnologías de la industrialización de los edificios de vivienda(5), expone también, de forma sintética y clara las características de aplicación del sistema y las formas de posible compatibilidad con otros sistemas constructivos.
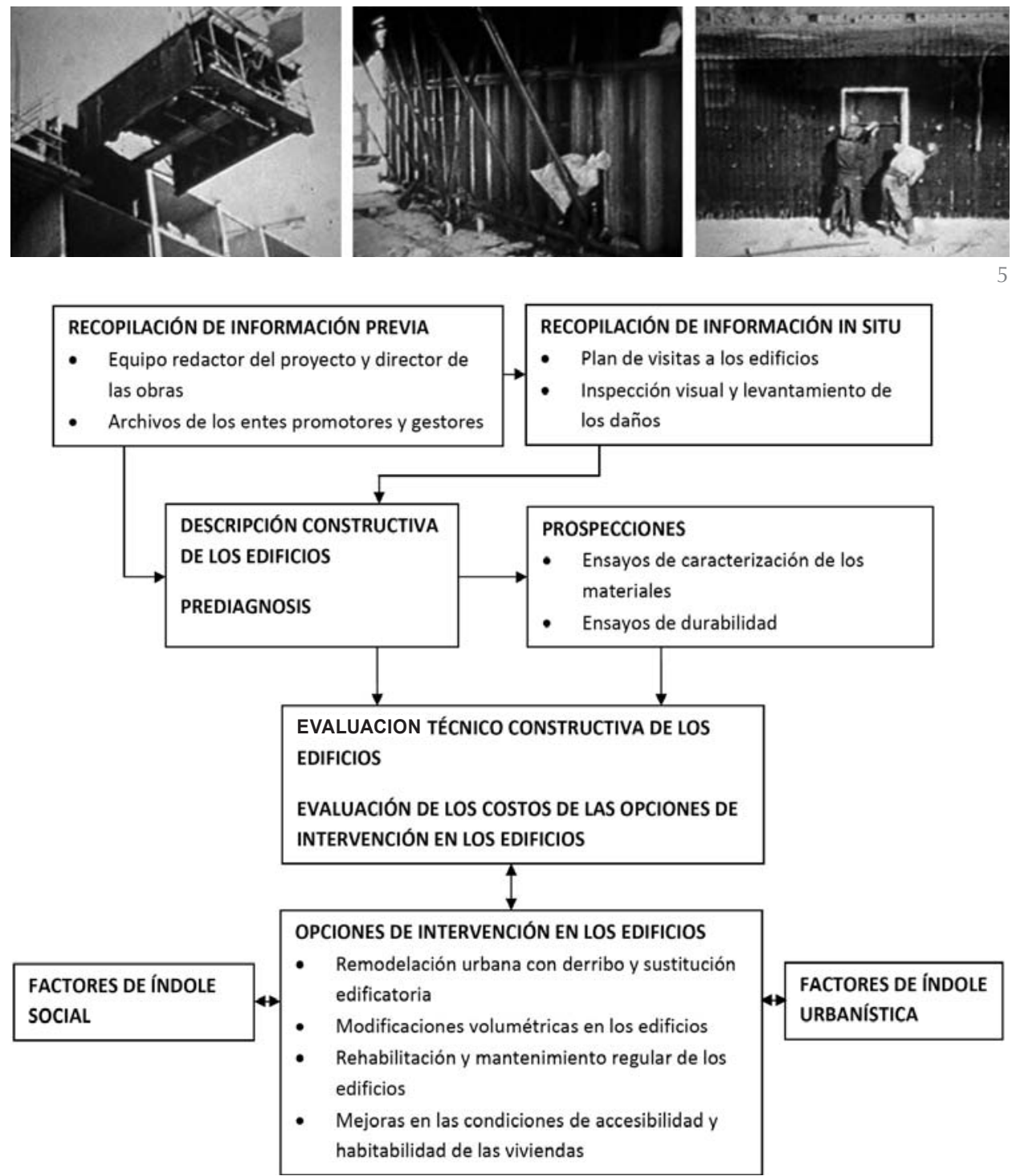

unidas rígidamente a losas macizas del mismo material. Se deduce de ello que el uso de dicha técnica obligue a adaptar el proyecto a ejecutar teniendo en cuenta las características y limitaciones del sistema constructivo aplicado $^{6}$ (figura 5).

\section{METODOLOGÍA APLICADA PARA EL ANÁLISIS Y LA EVALUACIÓN DE LOS EDIFICIOS}

La metodología aplicada para el análisis y la evaluación de los edificios se puede sintetizar en las fases y actuaciones siguientes:

a) Una fase inicial de recopilación de información previa sobre los edificios, a partir de consultas con los arquitectos autores y de los datos facilitados por los entes públicos gestores del barrio durante los años posteriores a su construcción.

b) Una fase de recopilación de información in situ, programando un plan de visitas por el exterior de los edificios, sus espacios Co- munes y el interior de las viviendas, con el fin de evaluar sus daños aparentes, estado de conservación y modificaciones funcionales más frecuentes.

c) Un plan de pruebas, cálculos y ensayos sobre diferentes elementos constructivos integrantes de los edificios.

d) Una última fase de cruce de los datos, ordenación de la información y elaboración de los resultados y de las opciones de intervención.

En el organigrama de la Figura 6 se visualizan las relaciones entre las diversas fases de análisis y su finalidad última de facilitar elementos objetivos para la definición del Plan de Transformación y Mejora del barrio.

\section{7. ÁMBITOS TEMÁTICOS DE ANÁLISIS Y EVALUACIÓN}

El estudio se ha estructurado en diversos ámbitos temáticos, de forma que de cada uno de 


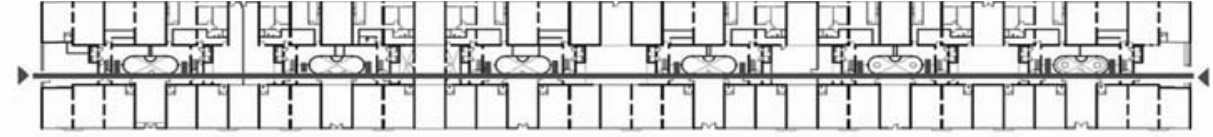

Planta Baja: Estado Original $>>>480$ viviendas/ acceso

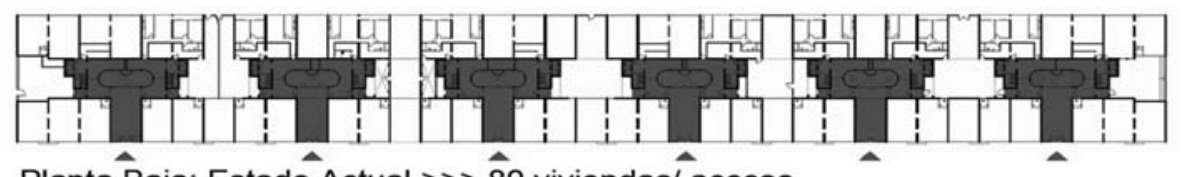

Planta Baja: Estadô Actual $\gg>\widehat{8} 0$ viviendas/ acceso

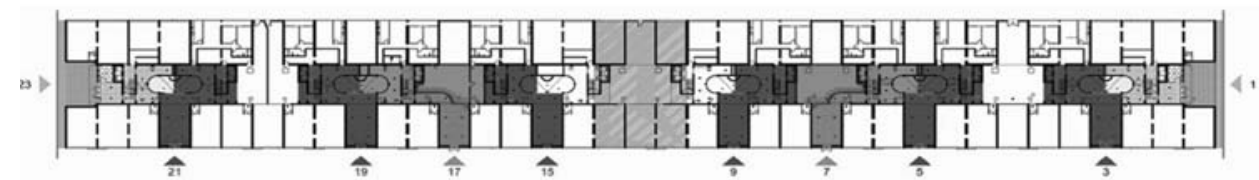

Planta Baja: Modificación proyectada $>>40$ viviendas/acceso

ellos se deducen consideraciones operativas sobre las intervenciones propuestas. Cabe distinguir los siguientes:

1) Aspectos tipológico-funcionales

2) Estructura y obra gruesa

3) Condiciones acústicas

4) Condiciones térmicas

5) Accesibilidad y evacuación

6) Instalaciones

7) Mantenimiento

En los siguientes parágrafos nos referiremos sucesivamente a cada uno de los temas citados.

\subsection{Aspectos tipológicos y funcionales}

El estudio sociológico desarrollado en paralelo al estudio técnico de los edificios relacionaba las carencias de mantenimiento de los espacios comunes (vestíbulos, escaleras, ascensores, etc.) con el elevado número de viviendas -concretamente 80 en la actualidad-servidas por cada acceso común de los edificios, lo cual, al dificultar el conocimiento mutuo entre los usuarios, favorece su desafección y obstaculiza su apropiación colectiva. Con antelación, el sistema de accesos de los bloques ya había sido modificado, puesto que inicialmente una única circulación longitudinal en cada bloque unía todos los vestíbulos y los accesos verticales. El reciente Plan de Transformación del barrio, con el fin de reducir al máximo el número de viviendas servidas por cada acceso vertical, propuso la subdivisión sistemática de todas las unidades de acceso, de forma que sirvieran sólo a 40 viviendas cada una. Dicha propuesta, que ha conllevado la remodelación completa de las plantas bajas de los edificios, ha sido ya ejecutada en su totalidad. La Figura 7 muestra gráficamente la solución original y las dos modificaciones sucesivas realizadas con posterioridad ${ }^{7}$.
En cuanto a los aspectos funcionales de las viviendas, fueron evaluadas en un plan intensivo de visitas directas a las viviendas, en las que se constató claramente que, en general, sus superficies y programas funcionales eran suficientes para los niveles de ocupación actuales, y que, concretamente, los edificios con encofrado-túnel no presentaban dificultades adicionales para la ejecución por parte de los usuarios de las modificaciones funcionales más habituales, tales como la supresión de una habitación o la independización del vestíbulo.

\subsection{Estructura y obra gruesa}

Los elementos estructurales y de la obra gruesa de los edificios a base de encofradotúnel están cimentados sobre un sistema de pilotaje con elementos debidamente arriostrados de $42 \mathrm{~cm}$ de diámetro y de 15 a $22 \mathrm{~m}$ de profundidad, en unos terrenos formados por arenas y limos, recibiendo cargas de 40 a $75 \mathrm{Tm}$ por pilote.

Se usaron dos modelos de encofrado-túnel, ambos con idéntica luz $(5,10 \mathrm{~m})$ y con el mismo grosor de los muros $(15 \mathrm{~cm})$ y de las losas de los forjados $(16 \mathrm{~cm})$. Los cerramientos exteriores son a base de paneles de hormigón prefabricados a pié de obra, recubiertos años más tarde por el exterior con chapa metálica plegada siendo las carpinterías de madera en su totalidad (Figuras 8 y 9). Las tabiquerías se construyeron con bloques de escayola de 6 y $7 \mathrm{~cm}$ de espesor.

Los edificios de 6 plantas de altura construidos con técnicas convencionales fueron ejecutados con estructuras porticadas de hormigón armado, forjados reticulares o de viguetas pretensadas del mismo material, y cerramientos exteriores a base de muros de fábrica de ladrillo visto o revestido.
7. Evolución de las diversas soluciones de acceso a los edificios del tipo $\mathrm{A}$. 

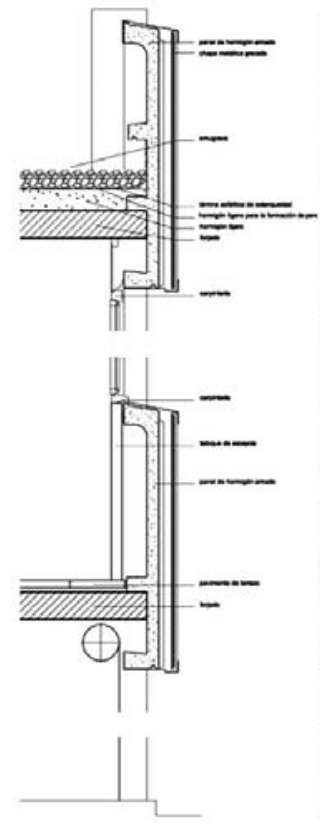

8. Detalle e imagen exterior del doblaje con chapa metálica sobre el panel de hormigón original.

9. Imagen exterior del panel original de hormigón (izquierda) y del posterior doblaje con chapa metálica (derecha).

${ }^{8}$ Dicho método es expuesto en el Manual para inspección de obras dañadas por corrosión de armaduras publicado por el Consejo Superior de Investigaciones Científicas (CSIC) (7). En el caso que nos ocupa se aplicó la versión del método propuesta por el Instituto Eduardo Torroja (IETCC) y el Centro Nacional de Investigaciones Metalúrgicas (CENIM), en la cual se toma como estimador del daño la disminución de la sección de acero, y como clasificación de los niveles de daño el adoptado por el CEB en su versión original.
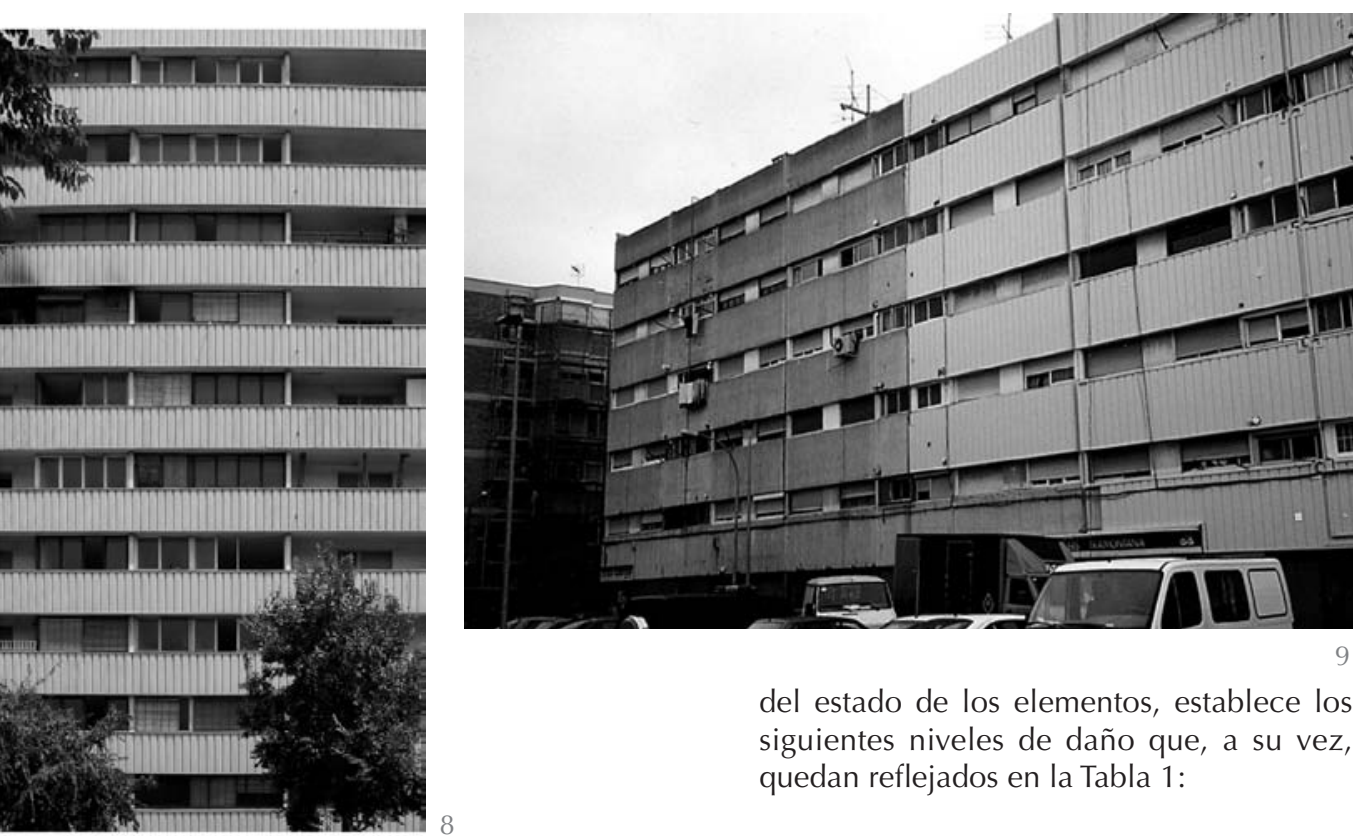

del estado de los elementos, establece los siguientes niveles de daño que, a su vez, quedan reflejados en la Tabla 1 :

Tabla 1

El edificio más alto del conjunto, de 14 plantas de altura, único en el barrio de dicha altura, se ejecutó también con la misma tipología estructural y con cerramientos de los mismos materiales.

Los sub-apartados que siguen se centran en el análisis de los edificios con encofrado-túnel.

\subsubsection{Inspección visual de los elementos estructurales}

Los aspectos más remarcables de la información recopilada sobre el estado y el comportamiento del sistema estructural se pueden sintetizar en los puntos siguientes:

- No se aprecian fisuras debidas a esfuerzos en los elementos estructurales, tanto en las zonas visibles del interior de las viviendas como en los muros exteriores de hormigón.

- Se perciben algunos síntomas incipientes y escasos en forma de fisuras y algunas pérdidas de material en aristas del hormigón visto de las fachadas. En cambio, las superficies planas de hormigón en contacto con el exterior se hallan, en general, en buen estado.

- Se detecta la presencia reiterada de fisuras en las tabiquerías de placas de escayola originadas por la flexión de las losas.

Con la información recopilada es posible establecer una estimación de daños por oxidación en los elementos de hormigón armado. Para ello se tomó como referencia la clasificación y método empírico de análisis propuestos en el Boletín 162 del C.E.B: "Relación de capacidad para elementos estructurales dañados por ataque químico" ${ }^{\prime \prime}$. El método, basado en la observación directa
Valores de resistencia residual de los elementos de hormigón armado en función de los niveles de daño observados y de la antigüedad de la construcción

\begin{tabular}{|l|c|c|c|c|}
\hline \multirow{4}{*}{ Construción } & \multicolumn{4}{|c|}{$\begin{array}{c}\text { Elementos de Hormigón } \\
\text { Armado }\end{array}$} \\
\cline { 2 - 5 } & \multicolumn{4}{|c|}{$\begin{array}{c}\text { Valores de resistencia } \\
\text { residual } \mu \text { para los diversos } \\
\text { niveles de daño }\end{array}$} \\
\cline { 2 - 5 } & $\mathrm{A}$ & $\mathrm{B}$ & $\mathrm{C}$ & $\mathrm{D}$ \\
\hline Nueva & 0,95 & 0,75 & 0,55 & 0,35 \\
\hline Antigua & 0,85 & 0,65 & 0,40 & 0,20 \\
\hline
\end{tabular}

- Nivel A: Corrosión de armaduras con pérdidas de sección en las barras principales del $1 \%$. Aparecen ligeras fisuras longitudinales en las esquinas coincidiendo con la situación de las barras, pero no fisuras transversales en el plano de los estribos.

- Nivel B: Corrosión de las armaduras principales con pérdidas de sección del 5\%. Salta el hormigón en las esquinas y quedan las armaduras principales al aire. Aparecen fisuras en el plano de los estribos. La capa de óxido hace que las armaduras pierdan adherencia en el hormigón.

- Nivel C: Corrosión de las armaduras principales con pérdidas de sección del 25\%. Se desprende el hormigón en la zona de los estribos y éstos quedan al aire. Pérdida de anclaje frente al pandeo y de adherencia de las barras. Se supone que el hormigón, por efecto de la corrosión se ha debilitado en una profundidad de $1 \mathrm{~cm}$.

- Nivel D: Rotura de estribos. La sección de acero que queda en las armaduras principales no trabaja. Las armaduras principales pandean. 
Mediante este tipo de análisis es posible deducir que los edificios estudiados se hallan en un nivel A de daño bajo, al presentar pérdidas de sección de acero inferior al 1\% y una fisuración no sistemática en algunas esquinas de los elementos de hormigón, de lo cual se deduce que su resistencia residual es asumible (Figura 10).
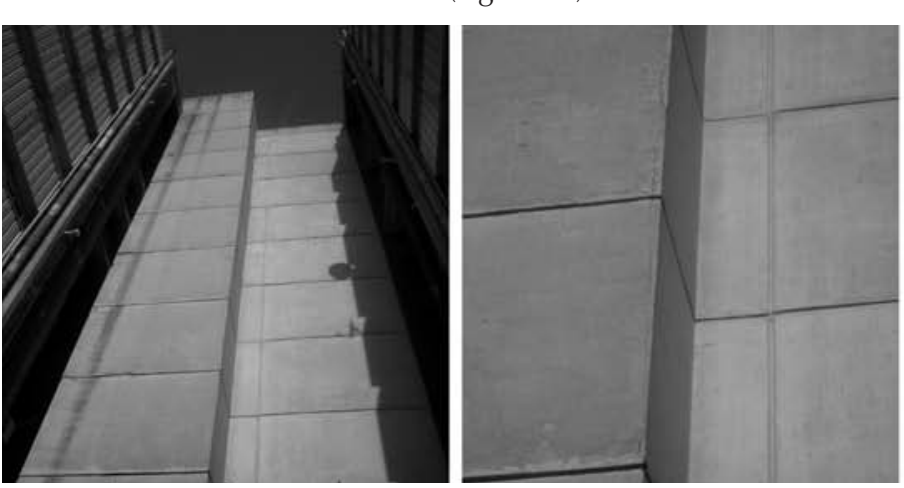

dieron en todos los casos valores no superiores al $0,02 \%$ sobre el peso de las muestras, los cuales se consideran contenidos insuficientes para incidir en la despasivación de las armaduras del hormigón. La localización de los ensayos se realizó a distancias variables del frente marino.

\subsubsection{Ensayos y cálculos realizados}

Los ensayos realizados en la estructura de muros y losas construidos con encofradostúnel fueron los siguientes:

- Extracción de probetas testigo. Se extrajo una muestra indicativa de probetas testigo de $7,38 \mathrm{~cm}$ de diámetro. Es preciso hacer constar que el objetivo del muestreo era ratificar que la resistencia estimada del hormigón utilizado en obra se avenía con la especificada en el proyecto del edificio, realizado en unas condiciones de control del material y de ejecución propias de los sistemas industrializados.

En la Tabla 2 se muestran los resultados de tensión de rotura a compresión estimada de las probetas, distribuidos por bloques de viviendas. De los resultados se deduce una resistencia estimada de rotura a compresión del hormigón $\mathrm{f}_{\text {ckest }}=25,4 \mathrm{~N} / \mathrm{mm}^{2}$, siendo la resistencia característica del hormigón que se utilizó en los cálculos de proyecto de $\mathrm{f}_{\text {ckproy }}$ $=18,0 \mathrm{~N} / \mathrm{mm}^{2}$.

- Límite elástico acero. Se realizó ensayo de tracción sobre una muestra de alambre liso de $5 \mathrm{~mm}$ de diámetro, estimándose un valor de límite elástico de $\mathrm{f}_{\text {ykest }}=540,4 \mathrm{MPa}$, siendo el valor de proyecto de $\mathrm{f}_{\mathrm{ykproy}}=500,0 \mathrm{MPa}$.

- Medida del estado de carbonatación del hormigón de los muros. Se detecta un frente de carbonatación variable entre 0,5 y 3 $\mathrm{cm}$, con una constante de carbonatación $\mathrm{K}_{\text {cmáx }}=5,47 \mathrm{~mm}$ /año. La localización de los ensayos coincidió con el de extracción de las probetas testimonio.

- Contenido de cloruros. Los ensayos realizados siguiendo los protocolos de la norma UNE-EN 1744-1/99 y NF-P-18583

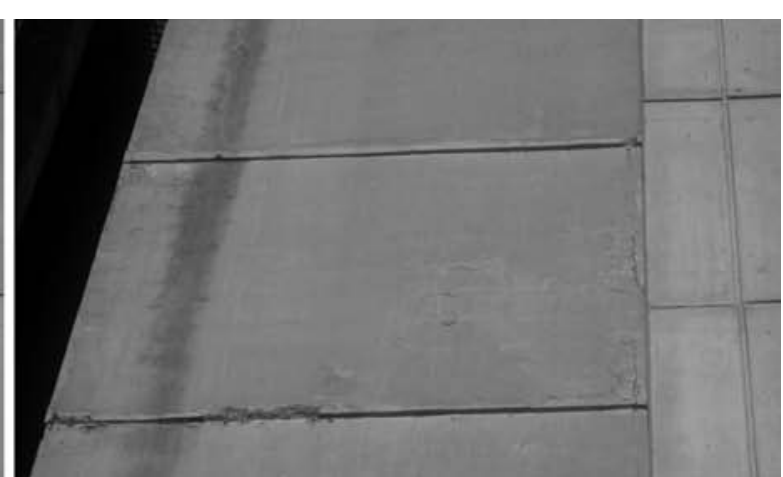

Tabla 2

Resultados de los ensayos de rotura de probetas testigo

\begin{tabular}{|l|c|c|c|c|}
\hline Situación & $\begin{array}{c}\text { Tensión rotura } \\
\text { corregida } \\
\mathbf{N} / \mathbf{m m}^{\mathbf{2}}\end{array}$ & $\begin{array}{c}\text { Tensión rotura } \\
\text { corregida } \\
\mathbf{N} / \mathbf{m m}^{\mathbf{2}}\end{array}$ & $\begin{array}{c}\text { Tensión rotura } \\
\text { corregida } \\
\mathbf{N} / \mathbf{m m}^{\mathbf{2}}\end{array}$ & $\begin{array}{c}\text { Tensión rotura } \\
\text { corregida } \\
\mathbf{N} / \mathbf{m m}^{\mathbf{2}}\end{array}$ \\
\hline Bloque A-1 & 27,1 & 26,5 & & \\
\hline Bloque A-2 & 42,4 & 37,3 & & \\
\hline Bloque A-3 & 32,6 & 38,1 & & \\
\hline Bloque A-5 & 28,7 & 25,1 & 29,9 & 26,9 \\
\hline Bloque A-6 & 30,0 & 35,5 & & \\
\hline Bloque A-6 & 30,2 & 23,1 & 25,5 & 28,1 \\
\hline Bloque F & 35,7 & 42,9 & & \\
\hline
\end{tabular}

A partir de los resultados obtenidos en los ensayos realizados se llevó a cabo la verificación analítica de los pórticos estructurales tipo de los bloques de 11 y 8 plantas con las características mecánicas de los materiales que constaban en el proyecto, aplicando la norma MV101-1961 para las acciones adoptadas y la Instrucción de 1968 para las hipótesis de cálculo. Ambas normas eran las vigentes en el momento de redacción del proyecto. Como ya se ha mencionado anteriormente los bloques analizados están construidos con estructura de muros y forjados macizos y continuos de hormigón armado vertido en obra, de 15 y $16 \mathrm{~cm}$ de grosor respectivamente, configurando una estructura monolítica hiperestática de nudos rígidos.

Las comprobaciones se realizaron considerando la combinación de esfuerzos más desfavorable y el peso de los paneles prefabricados de fachada. Los pórticos tipo se verificaron a los esfuerzos de compresión de los muros y de flexión de los forjados. También se verificó la deformación de las losas de los forjados (sin descontar sobrecarga de uso), la cual se evaluó en 1/893 de la luz, mayor, por tanto a la actualmente recomendable de 1/1000. 
11. Fisuración de los paneles de hormigón de una de las fachadas de los patios interiores de los bloques altos. Detalle del panel tipo.

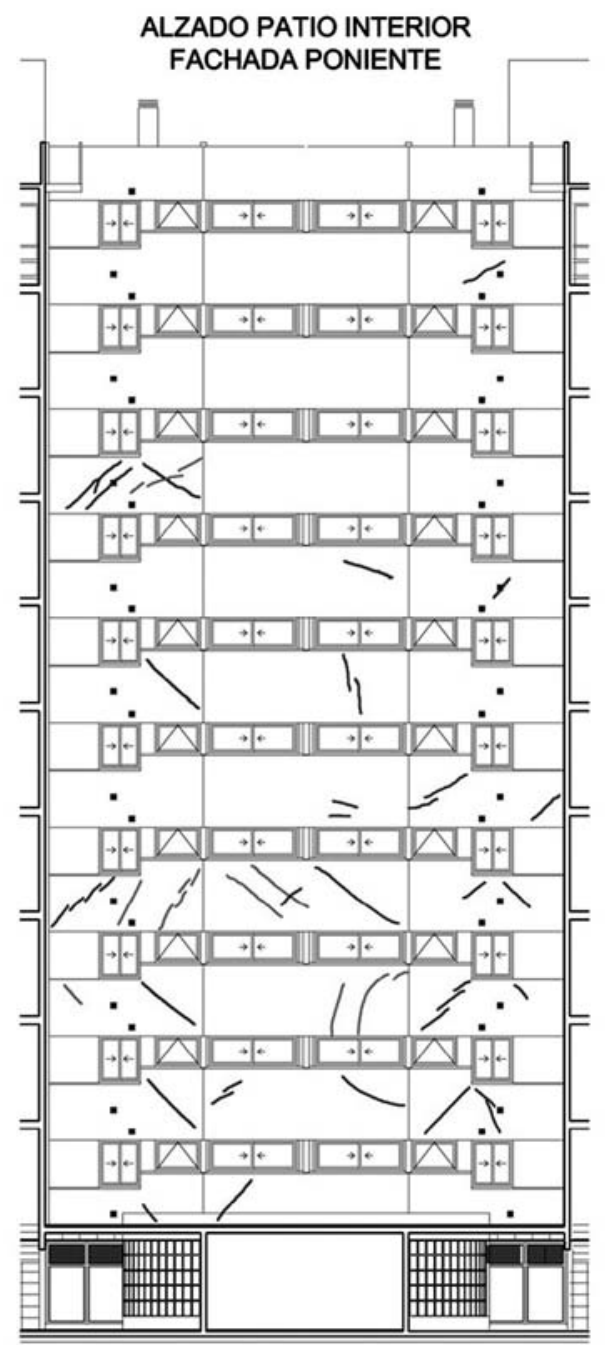

\subsubsection{Conclusiones sobre el estado actual de la estructura de los elementos con encofrado-túnel}

Del recálculo de la estructura se concluye que todos los edificios de La Mina Nueva, tanto los bloques del tipo A como los del tipo F, de 11 y 8 plantas de altura respectivamente, cumplen con las exigencias de seguridad establecidas en la Instrucción de 1968 vigente en el momento de la realización del proyecto, con respecto a su resistencia a las acciones verticales y a las horizontales generadas por el viento. Este hecho, sumado a la escasez de daños en forma de grietas de origen físico-mecánico o generadas por la oxidación de las armaduras, se deduce que la vida útil de los edificios a base de encofrado-túnel no será inferior a varias décadas, si bien la profundidad del frente de carbonatación, que alcanza en algunos puntos a las armaduras, aconseja la adopción a corto plazo de medidas de protección química de los paramentos vistos de hormigón. Por otra parte, la elevada resistencia estimada en los elementos resistentes del encofradotúnel en relación a la prevista en el Proyecto, derivada de la conveniencia de optimizar los plazos de desencofrado, confiere a dichos edificios un nivel de confianza adicional al

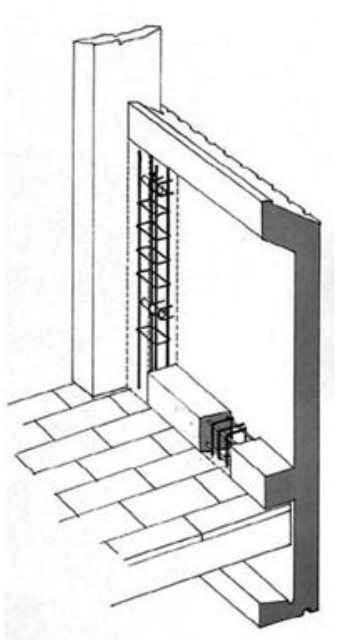

de las estructuras convencionales de la época, siempre y cuando se cumplan las condiciones de mantenimiento que demanda el hormigón visto, en atmósferas exteriores marítimas.

Cabe mencionar que la adopción de las normas en vigor en el momento de redacción del proyecto y realización de la obra se avendría con la prescripción del Código Técnico citada específicamente en el Anejo D del Documento Básico DB-SE referente a Seguridad Estructural.

Por lo que se refiere a la compatibilidad entre la estructura y el cerramiento cabe señalar que los edificios con sistema estructural en encofrado-túnel sufren la problemática de fisuración de las tabiquerías con intensidad similar a los ejecutados con estructuras convencionales porticadas de hormigón armado con losas planas aligeradas. Dicha problemática se reitera en otros muchos conjuntos residenciales de la época construidos con encofrado-túnel.

\subsubsection{Inspección visual de la obra gruesa de la envolvente exterior}

Se detectaron fisuras en los paneles prefabricados de hormigón armado de las fachadas de los patios interiores, en su mayor parte debidas a los esfuerzos de flexión de los propios paneles, a los sobreesfuerzos en el proceso de transporte y colocación de las piezas y a su acomodación posterior. Los paneles de las fachadas exteriores se diferencian sólo de los anteriores en el relieve del paramento visto con salientes verticales paralelos similares al grecado de las planchas. Dicho relieve se ha visto alterado con el tiempo por el desprendimiento del material más saliente y del más próximo a las zonas inferiores con mayor retención de agua, lo cual aconsejó disponer un doblaje con chapa metálica recubriendo la totalidad de los paneles. (Figuras 8 y 9).

En la Figura 11 puede observarse uno de los esquemas fisurativos típicos de las fachadas interiores y la resolución de los paneles prefabricados que conforman las barandillas y antepechos de las ventanas, apoyados en las losas de los forjados y fijados en los muros de hormigón armado.

Se verifica, por tanto, que los elementos de cerramiento a base de paneles de hormigón armado han requerido de intervenciones de reparación o prevención en plazos de tiempo inferiores a los de los elementos estructurales que los soportan. Por otra parte, las condiciones de exposición a la intemperie en que se hallan, hacen aconsejable proceder al sellado de las fisuras, al refuerzo de los paneles más afectados por fisuración y a la revisión sistemática de las sujeciones de los paneles de las barandillas expuestos a la intemperie por su intradós. 


\subsection{Condiciones acústicas}

Por lo que se refiere a las condiciones acústicas, la evaluación se centró en los edificios construidos con encofrado-túnel de la Mina Nueva. La situación física próxima a vías de alta intensidad de tráfico rodado de los tipos edificatorios $\mathrm{A}$ y $\mathrm{F}$ y, por tanto, su exposición a una fuente externa de ruido, fue el factor determinante para centrar el estudio en dichos edificios.

El marco normativo utilizado para la evaluación estuvo formado por la normativa básica de aislamiento acústico NBE-CA-88 y la Ordenanza general del medio ambiente urbano de Barcelona. Las dos normas eran vigentes en el momento de realización del estudio para edificios de nueva construcción y sirvieron como referencia al no haber ninguna normativa específica de obligado cumplimiento aplicable a la edificación existente cuando se construyeron los edificios.

Con respecto al ruido exterior los datos obtenidos fueron los siguientes (Figura 12).

- Niveles medios de presión sonora en el exterior de los bloques A y F: entre 58 y 66 dBA.

- Niveles medios de presión sonora en el interior de los dormitorios de los bloques $\mathrm{A}$ y F: entre 38 y $45 \mathrm{dBA}$.

No cumplen, por lo tanto, con las exigencias señaladas por las normativas citadas anteriormente, donde se exige, en ambas, un nivel de presión acústica interior máxima de 30 dBA para las diferentes estancias, $y$, concretamente, en el caso de la Ordenanza general del medio ambiente urbano de Barcelona una exigencia específica de $25 \mathrm{dBA}$ en el caso de los dormitorios. Cabe hacer mención que las fachadas de los edificios de La Mina Nueva no son una excepción con respecto al grado habitual del nivel de aislamiento de los ruidos del exterior en relación a la mayor parte de las fachadas de los edificios de la época, en la que no se fijaba umbrales mínimos de ruido y aislamiento acústico.

A la vista de estos resultados, en el estudio se propuso disponer doble acristalamiento en las ventanas de los dormitorios en los bloques más próximos a la vía de tránsito y la colocación de pantallas acústicas junto a la misma. Con respecto al aislamiento del ruido interior en las divisiones horizontales, la solución de forjado existente formada por una losa armada de $16 \mathrm{~cm}$ con pavimento de terrazo sobre mortero, proporciona un nivel de aislamiento frente al ruido aéreo de $58 \mathrm{dBA}$ frente a los 45 dBA que exige la NBE-CA-88.

Con respecto al nivel transmitido de ruido de impacto, se halla en el límite admisible:

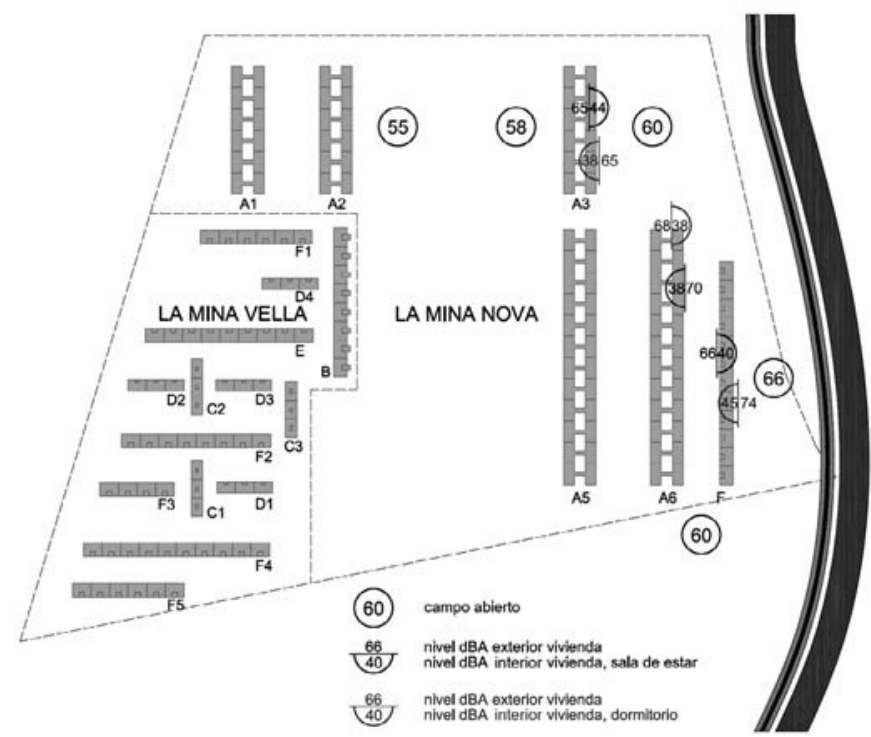

12

$77 \mathrm{dBA}$ frente a los $80 \mathrm{dBA}$ admitidos por la misma norma. En consecuencia, resultaba una solución suficiente.

Por lo que se refiere al aislamiento acústico en las divisiones verticales entre pisos se hizo una primera distinción entre los bloques $\mathrm{A}$ y F. Mientras que la separación entre viviendas de los bloques tipo F estaba formada por los muros estructurales de hormigón armado del encofrado-túnel, que proporcionaban un aislamiento acústico suficiente, la separación entre viviendas de los bloques de tipo A en la zona de dormitorios, se suponía resuelta, dada la información procedente de planos de obra, con un único tabicón de escayola de 7 $\mathrm{cm}$, al que le correspondía un nivel de aislamiento acústico de $35 \mathrm{dBA}$, cuando la NBECA-88 exigía un nivel de aislamiento mínimo de 45 dBA. Posteriormente, tras la realización de la reforma integral del módulo testero de uno de los bloques se pudo comprobar que esta separación estaba formada por un doble tabique de escayola de $7+7 \mathrm{~cm}$ sin cámara de aire interior, lo cual hacía innecesario un refuerzo acústico en la separación entre viviendas anexas.

Actualmente, tras la entrada en vigor del Código Técnico de la Edificación, éste no sería de obligado cumplimiento en las operaciones de mejora y mantenimiento a llevar a cabo en los edificios de la Mina, dado que no se prevé realizar en ellos intervenciones de rehabilitación integral. Por tanto, constituiría un referente adicional a la normativa anterior, susceptible de proporcionar valores orientativos sobre la calidad acústica de los edificios a evaluar. En todo caso, para verificar el cumplimiento de los requerimientos acústicos del CTE de las soluciones constructivas existentes sería necesario realizar medidas acústicas in situ. De todas formas, en el caso particular de
12. Niveles de presión sonora en el exterior e interior de los bloques cercanos a la vía de tráfico rodado. 

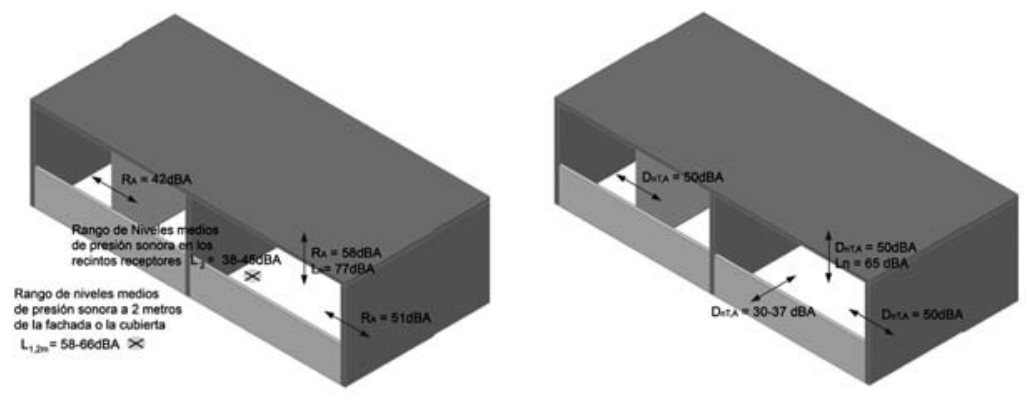

13

13. Comparación entre las medidas tomadas y los cálculos realizados sobre el aislamiento acústico proporcionado por los diferentes cerramientos (izquierda) y las exigencias a nivel acústico establecidas en el CTE (derecha).

14. Transmitancias térmicas de los cerramientos en sus soluciones originales y en sus soluciones en el momento de la realización del Estudio Técnico. los edificios construidos con encofradotúnel, las mediciones de presión sonora realizadas in situ en el interior y exterior de los edificios, permiten aproximar el valor del aislamiento acústico aéreo de la actual solución constructiva de fachada alrededor proporciona el doble tabique de escayola descrito anteriormente sería insuficiente, más aún si se consideran las transmisiones de ruido por los flancos, mientras que, en el caso de las divisiones horizontales la solución de forjado de losa armada de $16 \mathrm{~cm}$ con pavimento de terrazo sobre mortero proporciona un nivel de aislamiento frente al ruido aéreo de $58 \mathrm{dBA}$, valor que disminuiría en algunos decibelios con las pérdidas acústicas por los flancos, situándose probablemente en el límite del cumplimiento del CTE. El aislamiento a ruido de impacto a través de la losa de forjado sería insuficiente si comparamos los $\mathrm{L}=77 \mathrm{dBA}$ de nivel de presión de ruido asignados a esta solución constructiva que percibiría el usuario con los 65 dBA admitidos como máximo en el CTE (Figura 13).

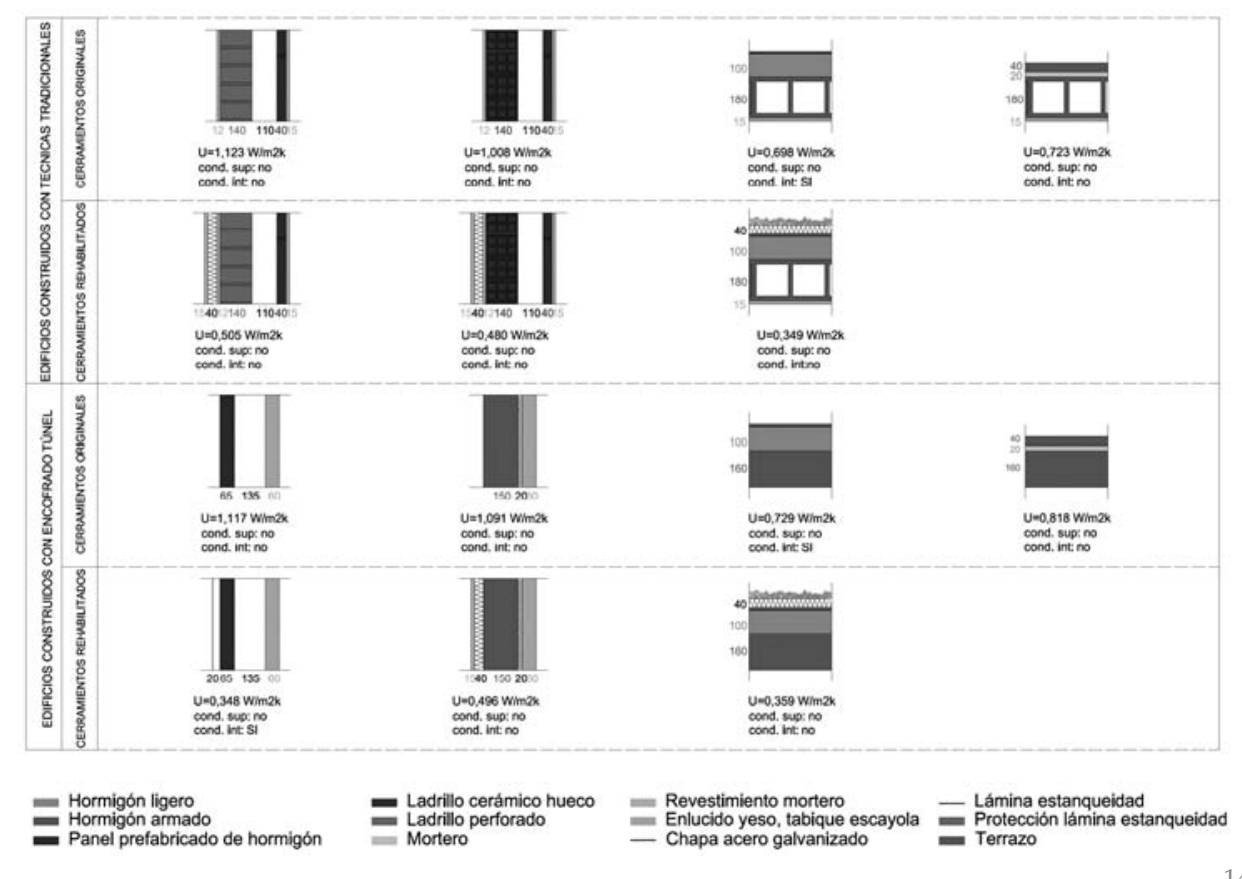

de los 20 dBA. Teniendo en cuenta los niveles de ruido exterior procedentes de las vías de tráfico rodado, los valores de aislamiento acústico aéreo exigidos a la solución de fachada variarían entre los 32 y los $37 \mathrm{dBA}$ para dormitorios y entre 30 y 32 dBA para el resto de usos. Se puede anticipar, por tanto, que sería necesario un refuerzo de aislamiento acústico, sobretodo en la parte vidriada, sustituyendo no únicamente los vidrios simples por vidrios dobles con cámara sino también el conjunto de carpintería. Por lo que se refiere a la separación entre viviendas, sería necesario llegar hasta los 50 dBA de aislamiento acústico en las divisiones tanto verticales como horizontales entre pisos contiguos. En el caso de las divisiones verticales el aislamiento acústico de 42 dBA que

\subsection{Condiciones térmicas}

El objetivo planteado consistía en introducir modificaciones o mejoras que permitiesen lograr unos niveles más actualizados de confortabilidad y ahorro de energía. El estudio se centró en los edificios de los tipos A y F construidos con encofrado-túnel, los cuales presentaban unas condiciones de aislamiento térmico presuntamente más escasas, dado que la mayor parte de los edificios construidos con técnicas convencionales ya habían sido objeto de mejoras térmicas integrales en sus fachadas y cubiertas.

Siguiendo un procedimiento similar al expuesto en el punto anterior, fue necesaria una fase de recopilación de información previa de las soluciones constructivas ini- 
ciales y de las intervenciones de mejora y mantenimiento que se habían efectuado posteriormente.

De cara a la evaluación de la transmitancia térmica de los cerramientos se tomó como referencia la normativa autonómica NRE AT/87 vigente en el momento del estudio. Aplicando el procedimiento establecido en dicha norma, se comprobaron los niveles de aislamiento en dos tipos de viviendas en ubicaciones diferentes dentro de los edificios: la correspondiente a las viviendas tipo, es decir, las ubicadas entre túneles intermedios, que eran las más reiteradas en términos cuantitativos, y la correspondiente a las situadas junto a un testero y bajo cubierta, en los extremos superiores de los edificios.

Los cálculos efectuados permitieron constatar que las condiciones de aislamiento térmico de todas las viviendas, incluso las que se hallaban en situaciones más desfavorables, superaban en los dos casos considerados los valores mínimos establecidos en la Norma de referencia. Cabe hacer mención que los edificios con encofrado-túnel analizados habían sido objeto de diversas operaciones de mejora de aislamiento térmico en sus cubiertas y testeros, y de una actuación de doblaje con chapa metálica de los paneles de fachada, que si bien su objetivo era evitar la caída de cascotes de hormigón de los paneles, incidía indirectamente en la mejora del aislamiento térmico de las fachadas. En el gráfico de la Figura 14 se muestran los resultados del cálculo de las transmitancias térmicas de los cerramientos iniciales y de los rehabilitados con antelación al estudio realizado.

Las anomalías en forma de humedades de condensación se detectaron, en escaso número, en los cantos de los muros junto a las carpinterías de fachada, en los tramos inferiores de los muros de la primera planta colindantes con pasos exteriores a través de los bloques en planta baja y en paramentos situados detrás del amueblamiento de algunas viviendas (Figura 15).

En la actualidad, la aplicación del Código Técnico como referente sería una premisa obligatoria, al superarse ampliamente los límites de superficie útil construida de 1.000 $\mathrm{m}^{2}$ establecido en dicho Código. Por otra parte, a diferencia de la manera de proceder en la evaluación de las condiciones térmicas de la Norma NRE AT/87 considerada, en donde las unidades de verificación son las viviendas en condiciones térmicas más desfavorables, en la evaluación térmica que se establece en el CTE únicamente se debe comprobar el cumplimiento de las transmitancias máximas establecidas en el propio Código, y la posible existencia de humedades de condensación
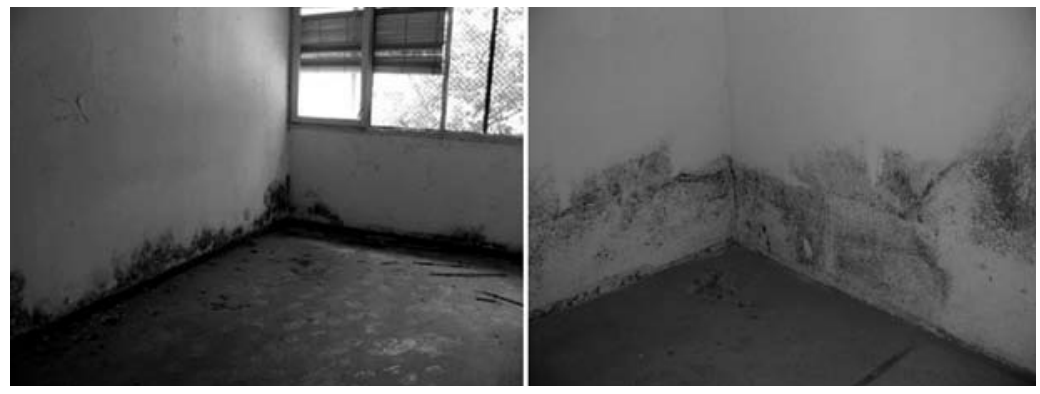

superficiales e intersticiales para cada uno de los diferentes tipos de cerramiento.

Al llevarse a cabo esta verificación en base al CTE se constata que se alcanzan los niveles de aislamiento térmico mínimos exigidos en las partes opacas de los cerramientos que ya han sido reforzados térmicamente con anterioridad. En cambio, sería necesario mejorar las condiciones térmicas de aquellos muros de obra vista de los edificios de la Mina Vella que no disponen de ningún tipo de aislamiento térmico ni por el interior de la cámara ni por el exterior. Por lo que se refiere a los huecos de fachada, se constata que los cerramientos existentes son en, su mayoría deficientes, con transmitancias que oscilan de entre 4,4 y $5,1 \mathrm{~W} / \mathrm{m}^{2} \mathrm{~K}$, cuando las máximas admitidas en el CTE oscilarían, según su orientación, entre 2,9 y $3,3 \mathrm{~W} / \mathrm{m}^{2} \mathrm{~K}$ para los edificios construidos con técnicas convencionales y entre 2,6 y $3 \mathrm{~W} / \mathrm{m}^{2} \mathrm{~K}$ y para los edificios construidos con encofrado-túnel. Por tanto, para el cumplimiento del CTE se precisaría la sustitución general de todas las ventanas de los edificios del barrio, incorporando nuevas carpinterías con vidrios dobles con cámara.

Por último, otro aspecto en el que también difiere el CTE de la normativa anterior es la exigencia de unas determinadas condiciones de protección solar, si bien en el caso de los edificios de la Mina, dada su situación geográfica en zona climática $\mathrm{C} 2$, y el porcentaje de huecos en fachada, que oscila entre el $26 \%$ y el $32 \%$, no haría necesario el cumplimiento de ningún factor solar modificado.

\subsection{Accesibilidad y evacuación}

Las intervenciones propuestas -algunas de ellas ya ejecutadas- son conceptualmente diferentes en los bloques de 6 plantas de la denominada Mina Vieja y en los bloques altos de 11 plantas ejecutados con encofradotúnel de La Mina Nueva. En los primeros, la intervención prevé la dotación de ascensores en todos los bloques que no disponían al no ser obligatorios en el momento en que se construyeron, a finales de los años 60 del pasado siglo (Figuras 16, 17, 18, 19), mientras que en los bloques altos la intervención propuesta se dirige a mejorar las condiciones
15. Efectos de las humedades en una de las viviendas de la primera planta. 
16. Plano del sector de La Mina Vieja con la ubicación de los nuevos ascensores. de evacuación en caso de incendio mediante la provisión de escaleras de incendios junto a los accesos verticales existentes.

Por lo que se refiere a los nuevos ascensores, se disponen por el exterior de los edificios complementando los accesos verticales existentes, haciendo coincidir los descansillos de cada nivel con los rellanos intermedios de las escaleras. Dicha disposición se consideró la

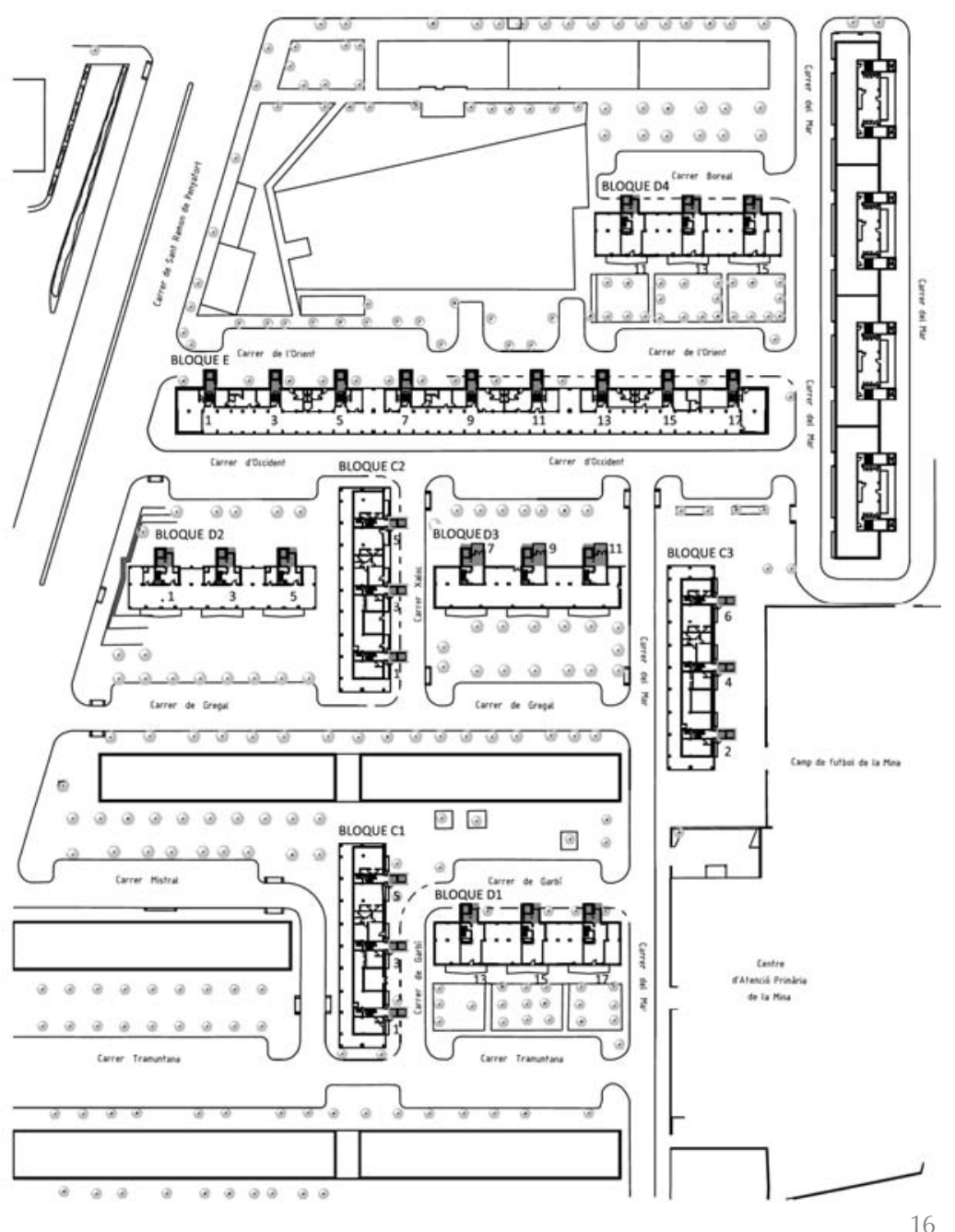

más adecuada por el organismo gestor, a pesar de no eliminar completamente la barrera arquitectónica del medio tramo de escaleras, dada la inexistencia de patios interiores y la dificultad de otras ubicaciones que hubieran supuesto mayores circulaciones horizontales a todos los niveles, reducción de privacidad y vistas en las viviendas y un costo muy superior. La tipología de los bloques, todos ellos de dos viviendas por planta y acceso vertical, facilitó la unificación de la solución volumétrica y constructiva para los 30 nuevos ascensores dispuestos, todos ellos con cerramientos a base de paneles prefabricados de hormigón armado y aberturas con carpinterías de aluminio. A lo largo del proceso de ejecución, la estructura porticada de hormigón aplicada en los primeros bloques, se varió en las fases sucesivas por estructuras con perfilería de acero, al adaptarse mejor a los pequeños lotes de hormigonado a que obligaba la obra y evitar la disposición de grúas fijas en cada bloque. Todos los interiores se recubrieron con paneles de laminado plástico termo-endurecido. El costo promedio por unidad de ascensor ha sido de $104.609 €$ (año 2008).

En los bloques de 11 plantas, a base de encofrado-túnel, todos ellos con 4 viviendas por rellano y tipología en $\mathrm{H}$ con acceso vertical central flanqueado por los patios interiores, se consideró conveniente mejorar las condiciones de detección y evacuación de humos en caso de incendio, sectorizando por la quinta planta los recintos de escaleras y previendo recorridos de evacuación desde dicha planta hasta la cubierta a través de nuevas escaleras de incendios dispuestas en los mencionados patios interiores. Se conseguía con ello posibilitar la evacuación en caso de incendios de las plantas superiores, aceptando la evacuación de las inferiores por las escaleras móviles de los cuerpos de extinción. La disposición de exutorios de activación automática en los recintos de escaleras de los accesos verticales (Figura 21) complementaba
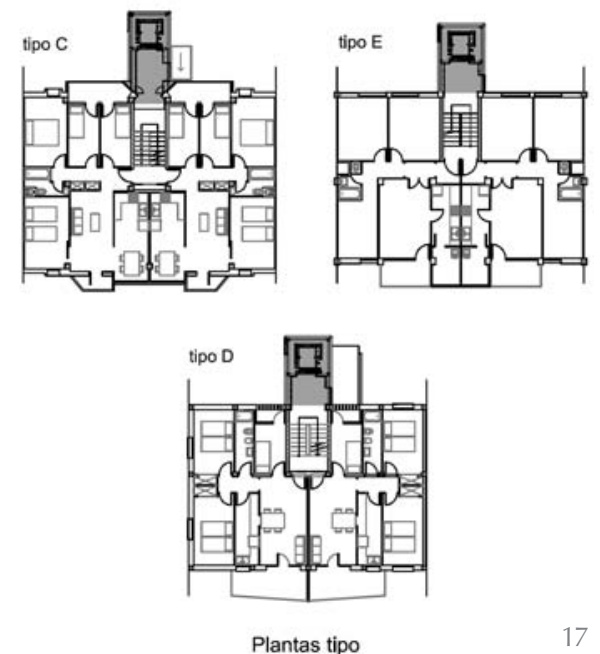

17
17. Situación de los nuevos módulos de ascensor en los diversos tipos de edificios.
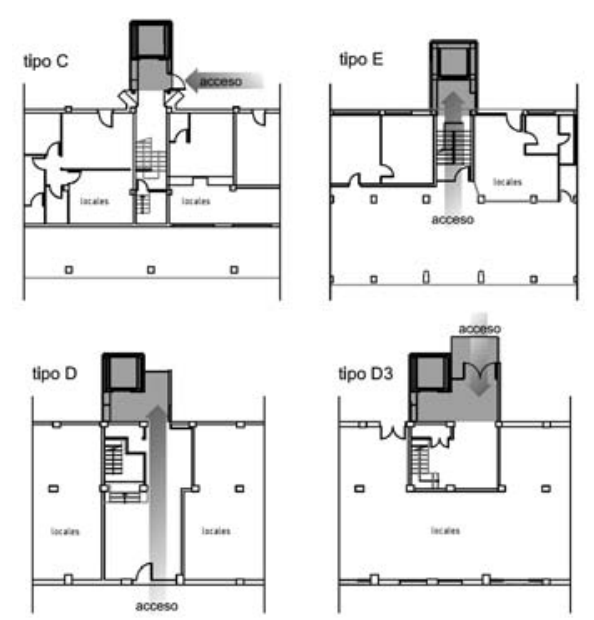

Plantas bajas 

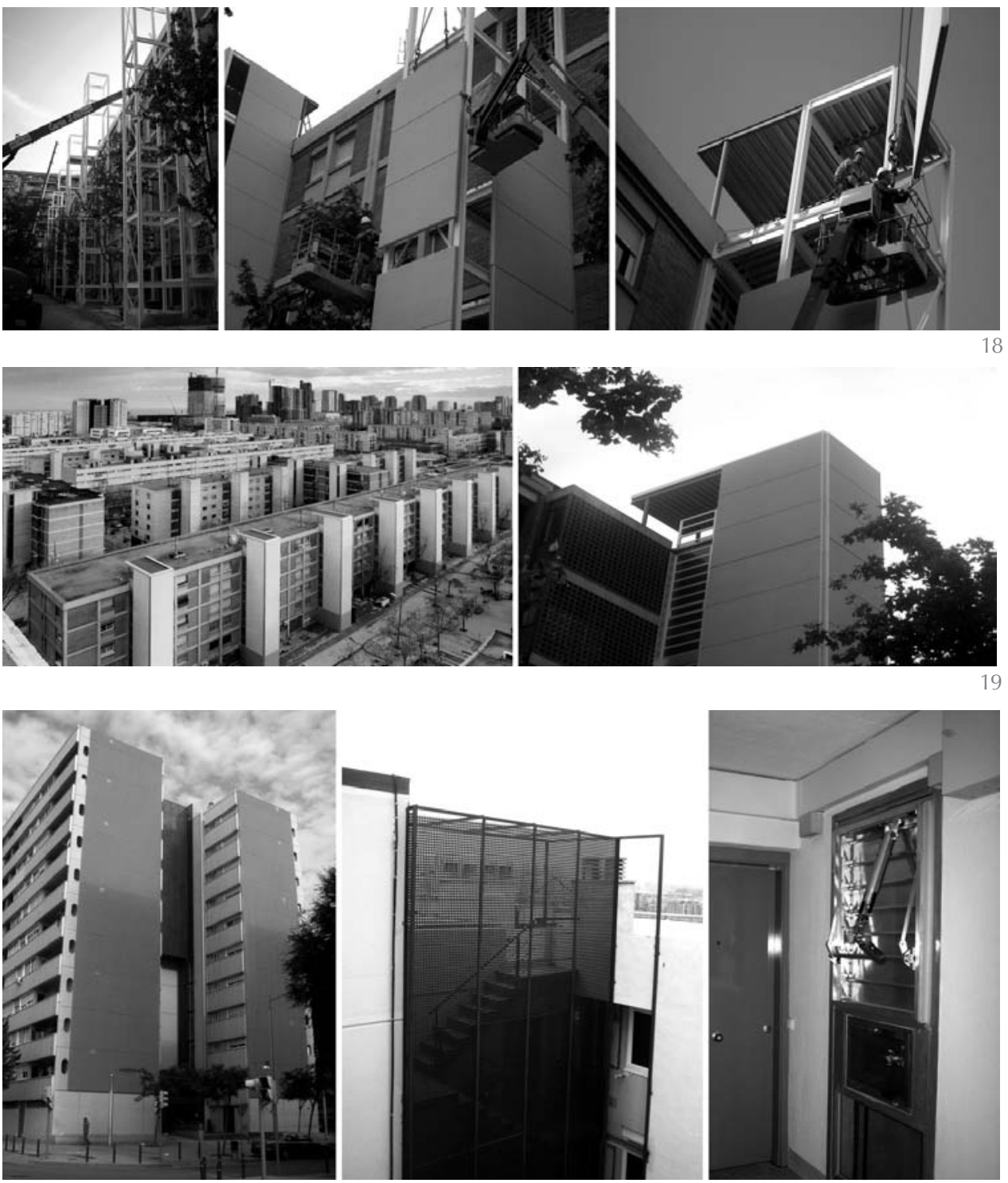

20

las nuevas medidas, propuestas todas ellas por los servicios técnicos de los cuerpos de bomberos. En la Figura 20 puede observarse también la escalera de incendios ya construida, correspondiente a uno de los módulos extremos de los edificios.

\subsection{Instalaciones}

Desde una perspectiva general, la evaluación del estado de las diversas instalaciones de evacuación, suministro de agua, electricidad, gas, telefonía y audiovisuales debe realizarse a partir del análisis de las operaciones de mantenimiento y mejora llevadas a cabo a lo largo del periodo de servicio de los edificios. De todas formas, como aspecto relevante y específico de las operaciones realizadas, cabe mencionar la necesidad de replanteamiento y práctica anulación del espacio previsto inicialmente como "bloque técnico" para el paso centralizado de los conductos de evacuación y suministro de agua de las cocinas y baños de las viviendas (Figura 21), al verificarse las negativas consecuencias de las actuaciones individuales inadecuadas en los conductos, las reparaciones defectuosas y parciales, y la insalubridad manifiesta de dichos espacios, que obligó al organismo gestor del mantenimiento a la eliminación de la mayor parte de los conductos que transcurrían por el interior del citado "bloque técnico", trasladándolos al exterior, con el fin de facilitar su inspección, reparación o registro selectivo.

\subsection{Mantenimiento}

Las operaciones de mantenimiento llevadas a cabo en los edificios no difieren, en general, de las ejecutadas en otros muchos conjuntos de viviendas de promoción pública construidas en el periodo 1960-1975, las cuales suelen abarcar la substitución de las instalaciones caducas y su adecuación a las nuevas exigencias normativas, la rehabilitación y mejora de las condiciones térmicas de los cerramientos exteriores y la adición de nuevas instalaciones de gas y telecomunicaciones.
18. Imágenes tomadas durante la ejecución de la estructura y la colocación de los paneles de hormigón armado.

19. Vista general de los bloques con los nuevos ascensores en La Mina Vieja (izquierda) y detalle del remate superior de los nuevos volúmenes (derecha).

20. Imágenes de la nueva escalera de evacuación en caso de incendio situada en el módulo extremo de uno de los edificios construidos con encofrado-túnel (izquierda y centro). A la derecha, conjunto de registro de columna seca y uno de los exutorios. 
21. Planos originales con la distribución de los conductos de evacuación de baños y cocinas e imagen de la previsión centralizada de paso a través de las losas de los forjados.

22. Comparación de costos entre las diferentes opciones de rehabilitación, sustitución edificatoria y mantenimiento para los bloques A y $\mathrm{F}$ construidos con encofrado-túnel.
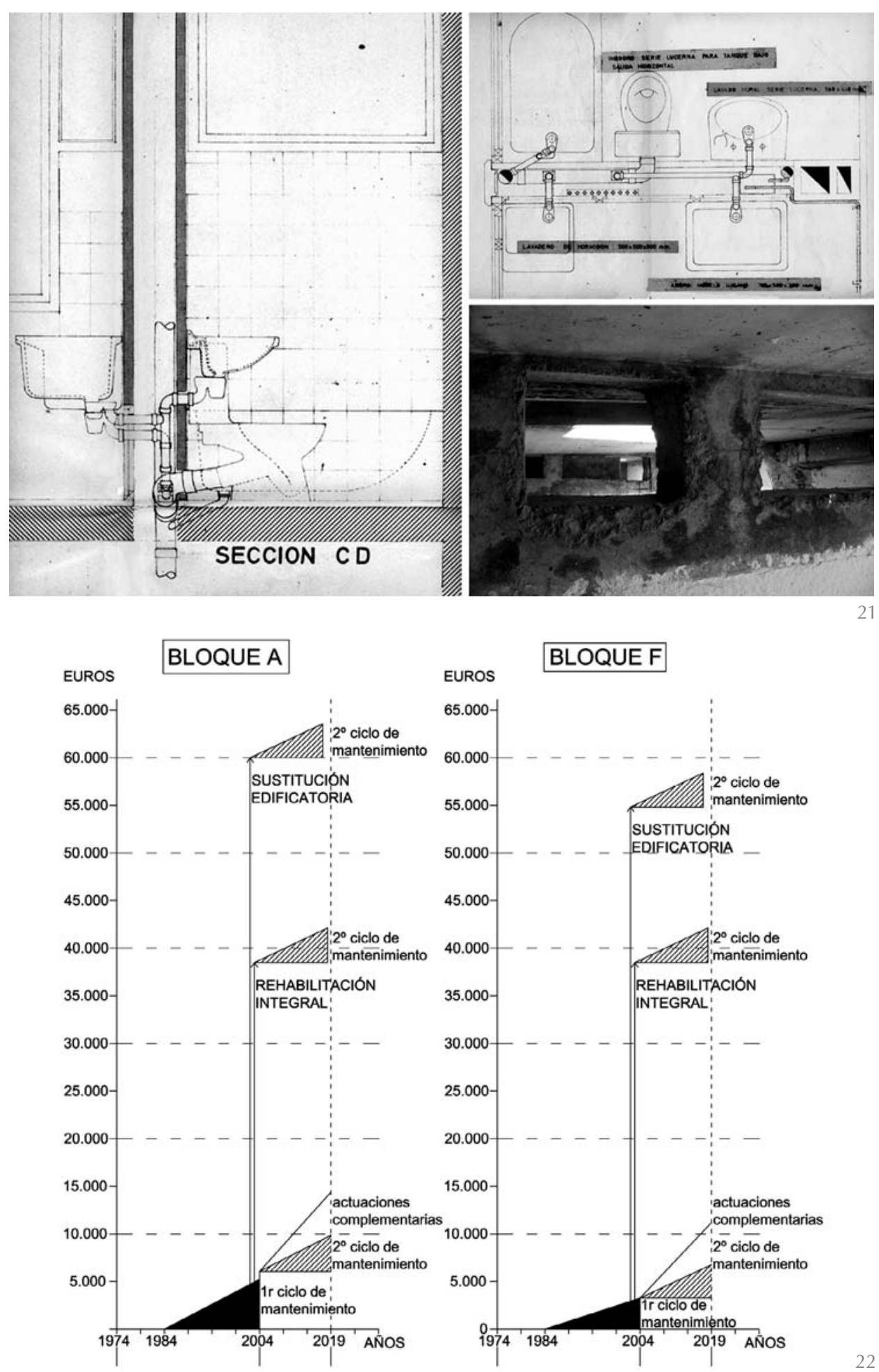

De forma más concreta, las operaciones realizadas o en curso de ejecución en los edificios de La Mina son las siguientes:

- Doblaje por el exterior de los paneles de hormigón de las fachadas con chapa metálica de $1,5 \mathrm{~mm}$ de grosor.

- Disposición de refuerzo de aislamiento térmico por el exterior de los muros testeros. - Formación de cubierta invertida, con dotación de material adicional de aislamiento térmico.

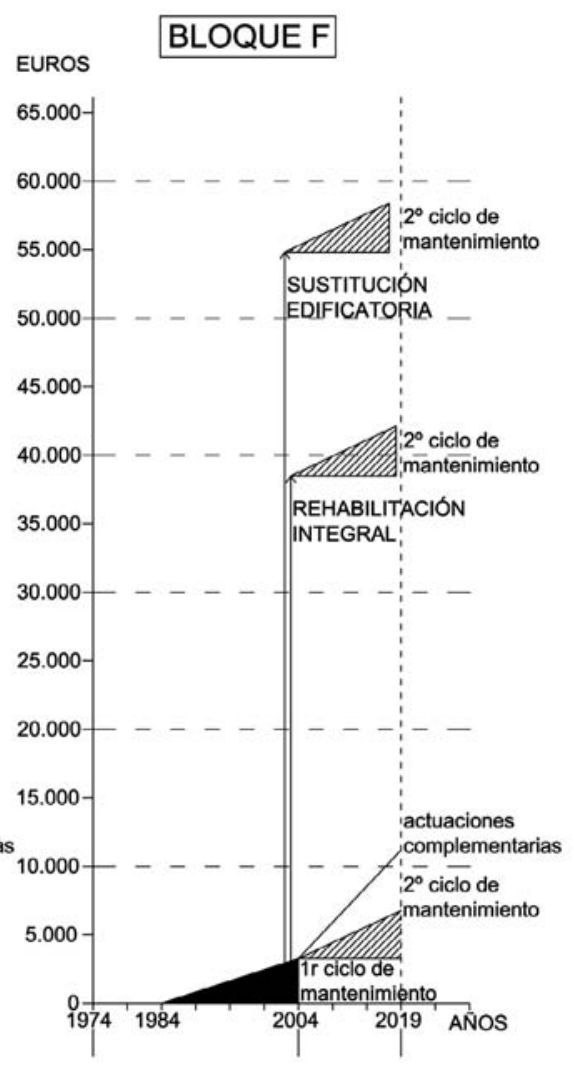

- Eliminación de los bloques técnicos, recambio y nueva disposición por las fachadas de los patios de los bajantes de aguas sucias.

- Nueva dotación de registro a las arquetas generales exteriores.

- Sustitución de las instalaciones de suministro de agua fría y de producción de agua caliente.

- Nueva dotación de gas natural, siguiendo las normas de la Cía. suministradora.

- Centralización de contadores de electricidad y adecuación de la instalación general 
a las normas actuales, con previsiones de potencia para el sistema de calefacción.

- Nueva dotación de instalaciones de telecomunicaciones.

- Nueva disposición de un tramo de escalera desde la última planta a la cubierta a utilizar como salida de emergencia.

- Operaciones diversas de rehabilitación de ascensores y vestíbulos generales.

Al analizar los costos globales de dichas intervenciones (Figura 22) se verificó que los correspondientes a un primer ciclo de mantenimiento (que abarca los 20 años iniciales, y que incluye la primera rehabilitación de cerramientos exteriores e instalaciones básicas y la subsanación de defectos o insuficiencias graves de la construcción original) no diferían sustancialmente de los costos promedio en otros conjuntos de viviendas de similares características, como se ha apuntado anteriormente. Se verificó también que no se produjeron diferencias de costo apreciables entre el conjunto de actuaciones realizadas en los edificios con técnicas convencionales y los realizados con encofrado-túnel, y que, en todo caso, las diferencias más remarcables se derivaban de la intervención de anulación y cegado de los bloques técnicos y de la renovación y desvío de las instalaciones que contenía, lo cual supuso un elevado costo 9 .

En la misma figura 22, se muestran los resultados del análisis de costos efectuado considerando opciones diversas de intervención en dos edificios representativos de La Mina Nueva con el fin de hacer factible su comparación. Las opciones consideradas fueron:

Opción a): Comprende las operaciones habituales de rehabilitación y mantenimiento ya realizadas en un primer ciclo de intervención y previsibles en un segundo ciclo. Se calculan también los costos de las operaciones complementarias previstas en el Plan Especial de Transformación y Mejora del barrio, que abarcan el refuerzo de aislamiento acústico entre viviendas, la adecuación de las vías de evacuación e instalaciones contra incendios ya comentados, la dotación de infraestructuras comunitarias de telecomunicaciones y la adecuación normativa de las instalaciones de evacuación de humos y gases quemados.

Opción b): Es la opción de sustitución de los edificios actuales por otros de superficie equivalente, adicionando los costos de mantenimiento habitual posteriores a su construcción.

Opción c): Es la opción de rehabilitación integral de los edificios, entendiendo con esta denominación la realización de operaciones, no solo de mantenimiento, sino de reparación de elementos estructurales, tales como por ejemplo el refuerzo o sustitución funcional de forjados, las cuales no son precisas en este barrio.

El conocimiento de los costos de estas opciones permite deducir, por una parte, que la sustitución edificatoria resulta mucho más onerosa que la opción del mantenimiento continuado, sean cuales sean las operaciones complementarias que comprenda, y por otra parte, que dicha opción sustitutoria también resultaría más onerosa si se presentara el supuesto de requerimiento de rehabilitación integral, por la presencia de problemas estructurales específicos.

\section{CONSIDERACIONES FINALES}

Las diferencias verificables en el comportamiento a lo largo de la vida útil entre los edificios construidos con técnicas convencionales y los construidos a base de encofrado-túnel no se asocian en su mayor parte a las características intrínsecas de dichos sistemas, sino a situaciones específicas derivadas de las condiciones de uso de las viviendas o de las decisiones de proyecto. Cabe citar, entre los edificios con técnicas convencionales, los altos índices de viviendas por acceso vertical y las condiciones de fácil acceso y registrabilidad a las instalaciones generales, y entre los edificios con encofrado-túnel con las que se relacionan con el material propio del encofrado-túnel, es decir, con el hormigón armado, que obliga a unas condiciones de mantenimiento más estrictas que los materiales cerámicos utilizados habitualmente en sistemas más convencionales. Estas consideraciones, se inducen directamente, por una parte, de la comparación entre las operaciones de mantenimiento extraordinario que ha sido preciso realizar para dificultar a los usuarios la accesibilidad a algunas instalaciones en los edificios con encofrado túnel con mayor número de viviendas por acceso, en relación al resto de edificios con menores índices de vivienda por acceso común, y por otra parte, de la comparación de los costos promedio que han requerido los cerramientos exteriores cerámicos en relación a los de hormigón.

Las reducidas exigencias de aislamiento acústico y térmico de las viviendas en el momento en que fueron construidas -sea cual sea el sistema constructivo utilizadoaconsejan la adopción de soluciones de mejora de ambos requerimientos, con el fin de dotarlas de unos niveles de habitabilidad y ahorro energético más acordes con las exigencias y demandas sociales actuales.
${ }^{9}$ Los valores sobre los costos de las operaciones de mantenimiento y reparaciones extraordinarias se contabilizaron a partir de la consulta de todos los expedientes de obras almacenados en los archivos de los entes gestores (Patronato Municipal de la Vivienda de Barcelona y Pla de Besòs, S.A.) desde la finalización de los edificios hasta el momento de la realización del estudio técnico encargado. Dichos datos se complementaron con el costo de las operaciones de rehabilitación integral emprendidas posteriormente y con los costos promedio de intervenciones tipo de reparación y obra nueva. Un mayor detalle referente al método aplicado puede consultarse en el número monográfico de la revista Papers, editado por el Institut d'Estudis Metropolitans de Barcelona (8). 
En relación a los sistemas estructurales a base de hormigón armado, los edificios con encofrado-túnel disponen de un nivel de seguridad adicional conferido por la alta resistencia a compresión del hormigón utilizado, muy superior a la estrictamente necesaria prevista en el proyecto. Es probable que esta circunstancia se presente en otros conjuntos construidos con el mismo sistema, si bien es preciso ratificarlo en cada caso.
Por último, resulta constatable que las alternativas de sustitución edificatoria resultan mucho más caras a medio y largo plazo que las alternativas de mantenimiento continuado, aún en el caso que incluyan actuaciones complementarias dirigidas a mejorar sus condiciones de seguridad y habitabilidad.

\section{BIBLIOGRAFÍA}

(1) Díaz, C.: Aproximació a l'evolució i al comportament derivat de les tècniques constructives utilitzades en els tipus edificatoris exempts destinats a habitatge econòmic a Catalunya (Període 1954-1976), Escola Tècnica Superior d'Arquitectura de Barcelona, Universitat Politècnica de Catalunya, Barcelona, 1986.

(2) Bilbabo, L.: Algunas consideraciones sobre la historia de la industrialización de viviendas durante el Desarrollismo (1960-1975): la aportación bilbaína al debate de la industrialización de la vivienda. Informes de la Construcción, Vol. 58, nº 502 (2006), pp. 59-62.

(3) Avellaneda, J.; González, J. M.; Marques, G.; Vidal, J.: La innovación tecnológica desde la promoción de vivienda pública: el Concurso de Innovación Técnica INCASOL. Informes de la Construcción, Vol. 61 (2009), pp. 87-100. doi: 0.3989/ic.09.002.

(4) Cabrera Fernández-Pujol, M.: Encofrados túnel, Sindicato Nacional de la Construcción, Departamento de Industrialización, Madrid, 1975.

(5) Del Águila García, A.: Las Tecnologías de la industrialización de los edificios de vivienda, Colegio Oficial de Arquitectos de Madrid, Madrid, 1986.

(6) High expectations. A guide to the development of concierge schemes and controlled access in high rise social housing, Department of the Environment, Her Majesty's Stationary Office (HMSO) London, 1994.

(7) Andrade, C.; Feliu, S.: Inspección de obras dañadas por corrosión de armaduras, Manual del Consejo Superior de Investigaciones Científicas, Madrid, 1989.

(8) Díaz, C.; Ferrer. A.; García, R.; Ulla, A.: Els Teixits edificats: transformació i permanència, Revista Papers de I' Institut d'Estudis Metropolitans de Barcelona, $n^{\circ} 15$ (1993). 